Article

\title{
Fatigue Endurance Assessment of DLC Coatings on High-Speed Steels at Ambient and Elevated Temperatures by Repetitive Impact Tests
}

\author{
Emmanouil Bouzakis \\ Department of Engineering, German University of Technology in Oman (GUtech), P.O. Box 1816, Athaibah, \\ Muscat PC 130, Oman; emmanouil.bouzakis@gutech.edu.om; Tel.: +968-2206-1129
}

Received: 29 April 2020; Accepted: 5 June 2020; Published: 7 June 2020

\begin{abstract}
Diamond-like carbon (DLC) coatings are used, among other contexts, on machine parts subjected to repetitive impact loads at ambient and elevated temperatures. Hereupon, the film load capacity may not be consistent when the operational temperature increases. The paper introduces experimental and analytical results, at room and elevated temperatures, for assessing the fatigue endurance to repetitive impacts of a DLC coating deposited on high-speed steel (HSS) specimens, corresponding to cases such as of coated valves and similar parts. The mechanical properties of the coating and its substrate were determined up to $400{ }^{\circ} \mathrm{C}$ via nanoindentations and a finite element (FE)-supported evaluation method. The coating's fatigue endurance was assessed via the repetitive impact test which simulates sufficiently the operational conditions of valves and other machine elements subjected to rebound impact loads. According to these results, the mechanical properties of the DLC coating remain almost stable up to a temperature of $350{ }^{\circ} \mathrm{C}$. However, the coating fatigue endurance to repetitive impact loads progressively worsens up to around $150{ }^{\circ} \mathrm{C}$ due to its increasing deformation imposed by the substrate strength deterioration. Over this temperature, prevailing failure mechanisms are the developed gradual coating decomposition, which increases the brittleness practically without hardness losses up to $350{ }^{\circ} \mathrm{C}$. The paper elucidates the mechanisms leading to the attained experimental results and it presents temperature-dependent coating fatigue endurance stresses determined via finite element method (FEM)-supported calculations.
\end{abstract}

Keywords: impact test; DLC coating; load capacity

\section{Introduction}

Diamond-like carbon (DLC) coatings are increasingly used, among other contexts, in the surface protection of various machine elements and tools against friction, corrosion, wear etc. [1]. Even though DLC coatings usually preserve mechanical properties up to $300^{\circ} \mathrm{C}$, stress-induced effects are well-known for inducing graphitization at much lower temperatures, as described in the references [2-4].

In this way, the operational temperatures and loads may deteriorate the coating's and substrate's mechanical properties, as well as the coating's structural stability, thus, leading to undesired damages [5]. In order to assess the reliability of a coating deposited on a certain machine element, it is crucial to consider the effect of potential substrate properties deterioration on the occurring coating loads and to apply test methods simulating sufficiently the operational conditions of the coated part. The repetitive impact test is a convenient experimental procedure for testing coated parts subjected to impact loads such as valves, cutting tools etc. [6-8]. The obtained results, in combination with a finite element method (FEM)-supported simulation of this test, render possible the determination of Smith- and Wöhler-like diagrams describing the fatigue endurance of thin hard coatings commonly after $10^{6}$ impacts at various impact loads and temperatures $[9,10]$. To elaborate the latter diagrams, coating and 
substrate constitutive laws are considered, defined via a finite element (FE)-based evaluation method of nanoindentation results [11-14].

Many publications deal with the thermal stability of DLC coatings as, for example the references [15-17]. However, there is a lack of research aiming at elucidating the interaction of thermal and mechanical loads that determine the failure mechanisms of DLC coatings and their fatigue endurance. Moreover, temperature-dependent substrate material properties may also affect the triggering and evolution of these mechanisms. In the present paper, using the repetitive impact test, the failure mechanisms of a DLC coating deposited on a high-speed steel substrate subjected to repetitive impact loads at various temperatures are clarified. Depending on the coating structure, chemical composition [18] and operational temperature, mechanisms like the desorption of hydrogen and hydrocarbon fragments [15] as well as a crystalline structure conversion $[16,17]$ are activated propagating the coating brittleness and restricting its load capacity. These phenomena, in combination with the altering substrate properties versus the temperature, affect the coating fatigue endurance and restrict the fatigue endurance safe region of a Smith-like diagram, as described in the following. Hence, the knowledge of temperature-dependent coating fatigue endurance stresses is necessary for coatings deposited on machine parts subjected to repetitive impact loads.

\section{Materials and Methods}

In the conducted investigations an electro-magnetic impact tester, manufactured by the Impact-Bz Ltd. (London, UK) was used for acting repetitive loads on the coated specimens [6] (see Figure 1a). Using this device, impact times of less than $1 \mathrm{~ms}$ and strain rates of about $200 \mathrm{~s}^{-1}$ can be realized. The power supply module supports the whole arrangement. The output voltage is fully controllable, with the aid of a variable transformer for adjusting various impact force amplitudes. A personal computer (PC) equipped with a PID (proportional-integral-derivative) controller supervises the whole experimental procedure. The time course of an impact force signal at $1200 \mathrm{~N}$ is illustrated in Figure $1 \mathrm{~b}$. The signal grows almost linearly versus the impact time, reaching its maximum value at approximately $0.45 \mathrm{~ms}$ impact time. This time course remains constant in the sequential impacts, as can be observed in Figure 1c. The impact time of the applied forces in the conducted impact tests was held constant and approximately equal to $0.45 \mathrm{~ms}$. This time is practically equal to the corresponding one exercised on the considered machine elements during their operation.

During the impact test the ball indenter penetrates periodically into the coating under a desired maximum load as exhibited in Figure 2a. Depending on the impact load and on the number of impacts, a coating failure may occur. Hereupon, under a critical force, no coating failure after $10^{6}$ impacts develops, as presented in the diagram (see Figure 2a). Furthermore, a Wöhler-like diagram can be determined, as illustrated in Figure $2 b$. The shadowed region of this diagram is associated with the coating continuous fatigue endurance stress. The stress-strain data of this physical vapor deposited (PVD) film, as well as those of the cemented carbide substrate, are shown in Figure $2 b$. The axisymmetric FE model for calculating the coated surface response was developed on the platform of the ANSYS software (Release 10.0, ANSYS, Inc., Canonsburg, PA, USA), as described in reference [7]. For meshing the two-dimensional geometry of the carbide ball, coating and substrate plane elements were employed. Appropriate contact elements with variable stiffness $\mathrm{cs}_{x}, \mathrm{cs}_{y}$ in normal and tangential directions, respectively, were applied, to consider the coating adhesion. These contact stiffness data correspond to the stiffness of a well-adherent coating on a ground and micro-blasted substrate [18]. With the aid of calculations based on this FE model, the stress fields developed in the coating during the loading and unloading impact test stages were obtained. In the presented case, the film damage due to fatigue starts at the intensively stressed area in the vicinity of the formed imprint. Considering these results, the coating Smith- and Wöhler-like diagrams, illustrated in Figure 2b, are then created. The coating fatigue endurance limit in the demonstrated coating case amounts approximately to $2.8 \mathrm{GPa}$, which corresponds to an impact load of $400 \mathrm{~N}$. The coating withstands a theoretically infinite number of impacts, when it is stressed under this fatigue endurance stress. 


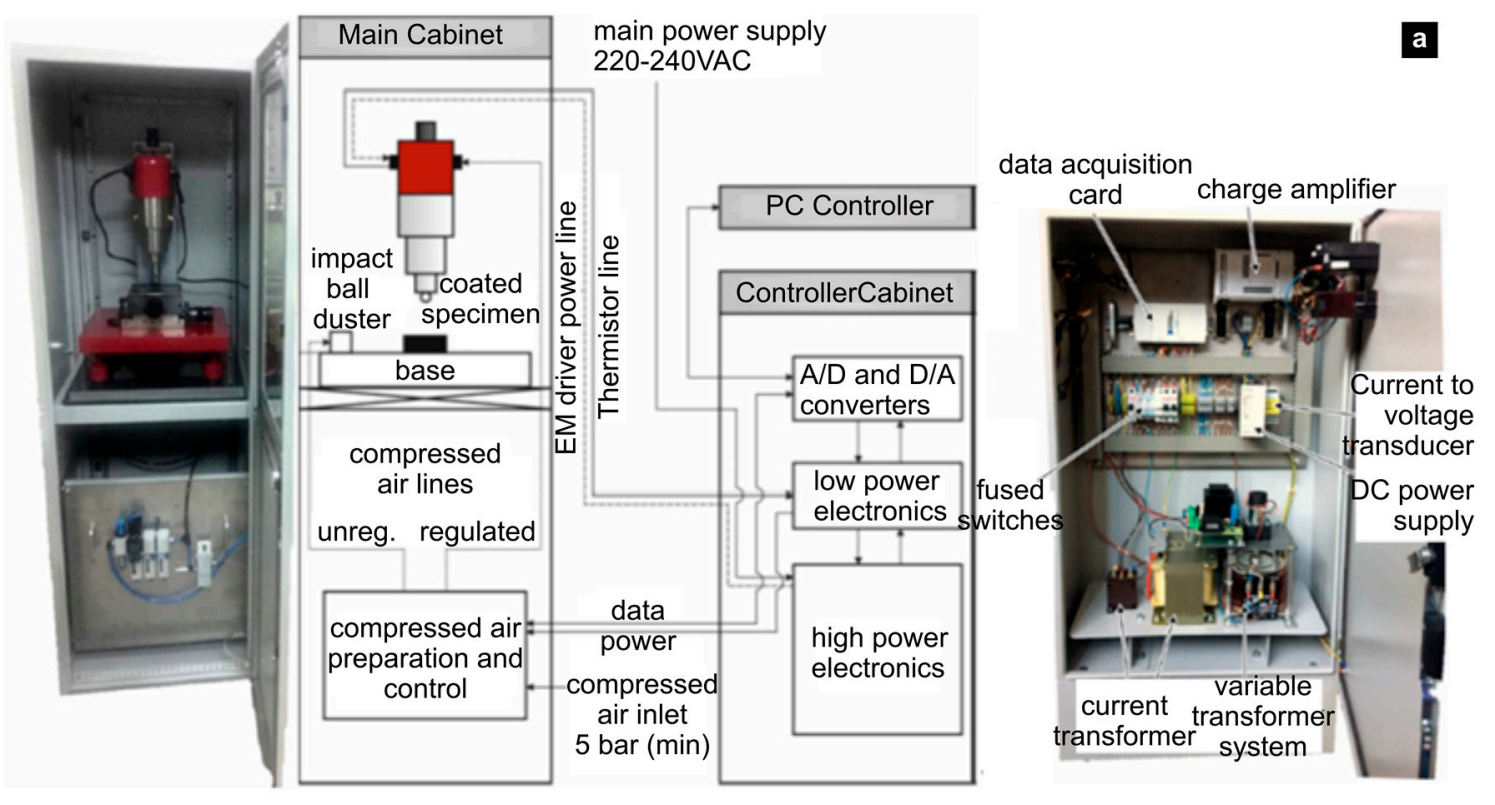

b
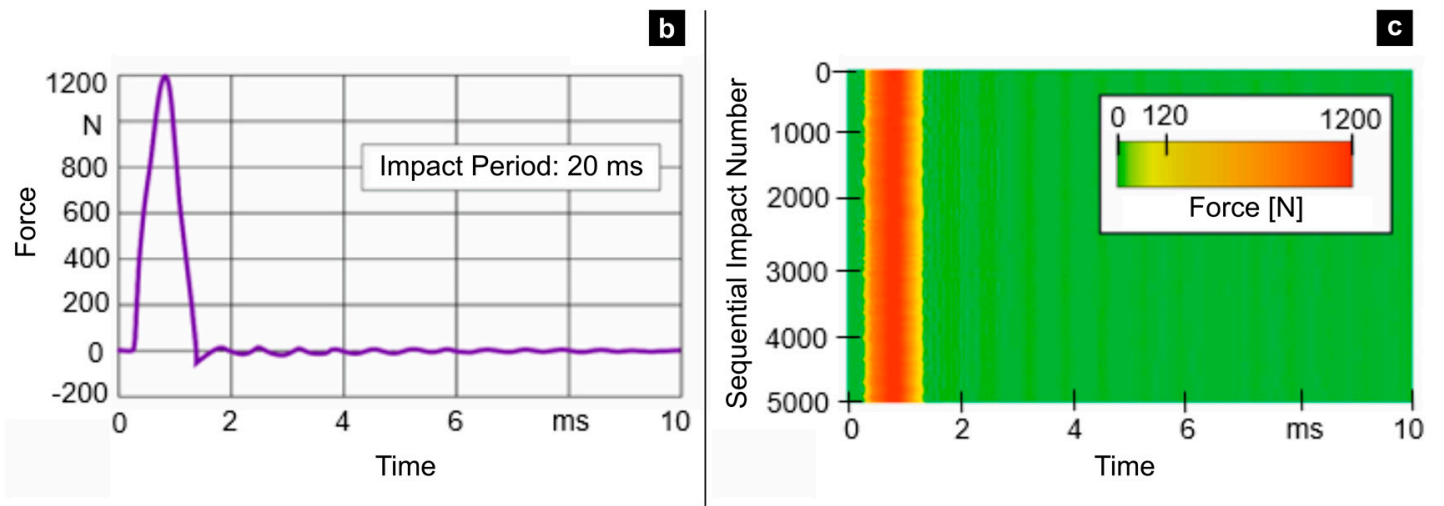

Figure 1. (a) Applied electro-magnetic impact tester for impact durations of less than $1 \mathrm{~ms}$; (b) impact force course versus the time; (c) impact force at the sequent impacts.

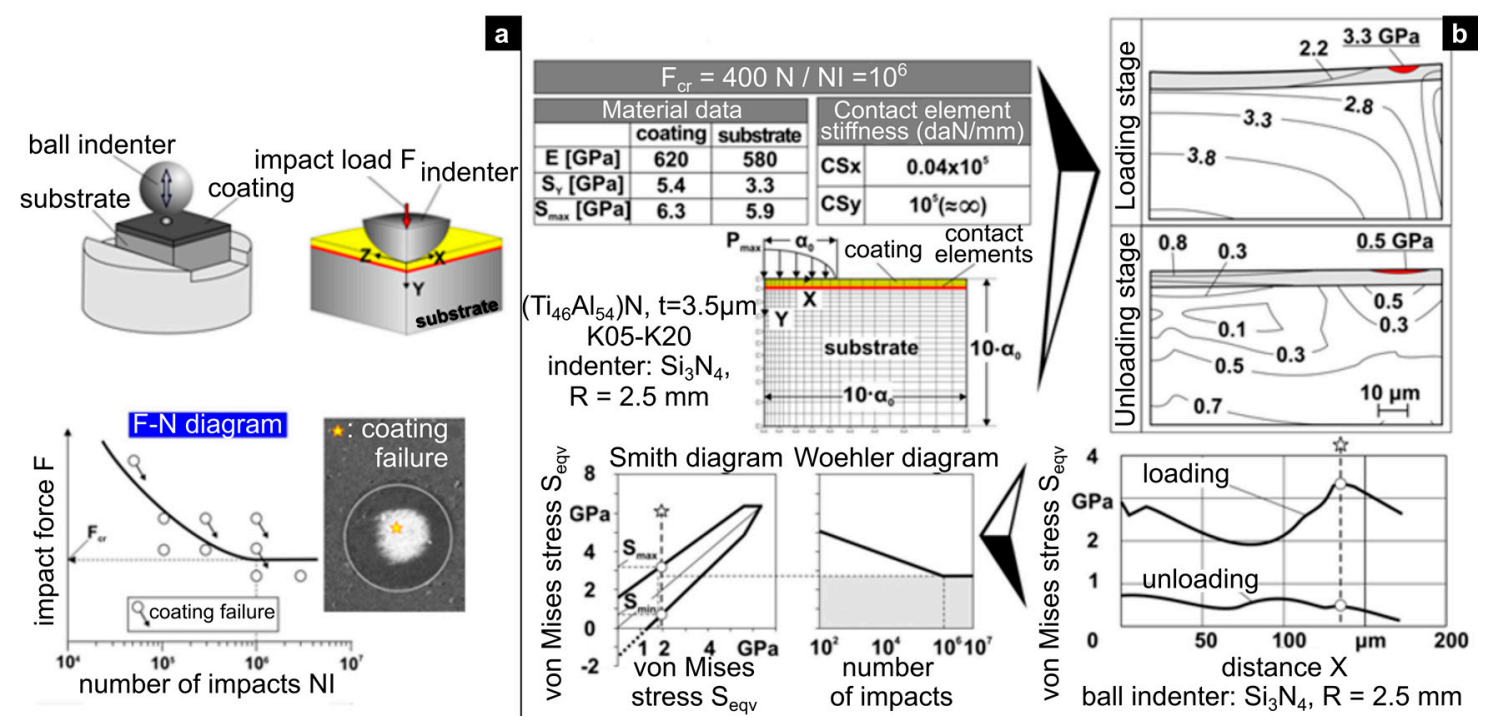

Figure 2. (a) Impact test procedure; (b) determination of the fatigue critical impact force and construction of coating's Smith- and Wöhler-like diagrams. 
A monolayer DLC film was deposited by an industrial CC 800/9 coating unit of CemeCon AG on high-speed steel HS 6-5-2 substrates via PVD magnetron sputtering. Before the coating deposition, the substrates were cleaned by ultrasonic washing with alkaline detergents, rinsed with de-ionized water, cleaned with isopropanol, and air-dried. For obtaining an improved coating-substrate adhesion, prior to the PVD process, argon etching was conducted, and a Cr interlayer of few nanometers was deposited. The coating thickness amounts to $3 \mu \mathrm{m}$. According to the procedures described in [18-20] the coating adhesion was characterized as good.

For determining the course of the penetration depth versus the indentation load of the coating and its high-speed steel (HSS) substrate at elevated temperatures up to $400{ }^{\circ} \mathrm{C}$, nanoindentations were conducted by a device of Micro Materials Ltd. using a Berkovic indenter (Wrexham, UK). At ambient temperature, the corresponding measurements were performed by means of a Fischer scope H100 device (Fischer Technology Inc., Windsor, CT, USA) employing a Berkovic indenter too. A scanning electron microscope (SEM) of JEOL Ltd. (Tokyo, Japan) was applied for determining the failed area ratio of the coating after the repetitive loads at various temperatures. The dimensions of the developed imprints after the impact tests were monitored using the confocal microscope $\mu$ SURF of Nanofocus AG (Oberhausen, Germany).

The penetration depth versus the indentation force diagrams are the input data to an FEM algorithm for defining the stress-strain curves of substrate and coatings at ambient and elevated temperatures, as described in the references [11-14].

The Raman spectroscopy on the as deposited as well as the annealed at $300{ }^{\circ} \mathrm{C}$ DLC coatings was carried out using a LabRAM HR spectrometer (HORIBA, Ltd., Kyoto, Japan).

\section{Results and Discussion}

\subsection{Determination of the HSS Substrate Temperature Depended Strength}

A main advantage of high-speed steels is that they retain their high hardness at a temperature of approximately $580{ }^{\circ} \mathrm{C}$. However, as the temperature increases from an ambient one up to about $350{ }^{\circ} \mathrm{C}$, the hardness of their martensitic structure and consequently their mechanical properties decrease continuously. This happens due to the precipitation of the carbon trapped in solution and the associated reduction of crystal lattice tension. Although the precipitation of the carbides acts against this process, a hardness reduction occurs during annealing up to around $350{ }^{\circ} \mathrm{C}$. Over this temperature, further phenomena are activated leading to a hardness increase known as the secondary hardness effect [21].

In the present paper, operational temperatures of DLC-coated high-speed steels up to $400{ }^{\circ} \mathrm{C}$ were considered. According to the previous explanations, a continuous worsening of the substrate properties develops up to approximately $350^{\circ} \mathrm{C}$. In this way and at constant operational load, when the temperature grows up to $350^{\circ} \mathrm{C}$, the substrate's and consequently the coating's deformation grow affecting their failure resistance and restricting their load capacity.

To determine the high-speed steel substrate mechanical properties at ambient and elevated temperatures, nanoindentations were performed. The diagram of the conducted nanoindentations on the uncoated HSS substrates at ambient temperature is illustrated in Figure 3a. This curve describes the mean value of 40 measurements. The latter curve, in the present specimen roughness case, is stabilized after approximately 25 indentations [12].

Considering these results, the substrate stress-strain curve was determined, applying the methods introduced in the references [11-14]. This curve and the corresponding Young's modulus, yield and rupture stress are displayed in the table of Figure $3 \mathrm{~b}$.

For establishing the substrate mechanical properties' dependence on the temperature, further nanoindentations up to $400^{\circ} \mathrm{C}$ have been performed, and as previously described, the related stress-stain curves were defined (see Figure 4a). Considering these constitutive laws, the course of the yield (SY) and rupture stress (SM) over the temperature is monitored in the diagram of Figure $4 \mathrm{~b}$. 
The expected reduction of the mechanical properties up to approximately $350{ }^{\circ} \mathrm{C}$ is visible and can be associated with the gradual reduction of crystal lattice tension, as previously explained. The properties' recovery over $350^{\circ} \mathrm{C}$ is imposed by the precipitation of extremely finely distributed carbides from the martensite phase and over approximately $450^{\circ} \mathrm{C}$ from the residual austenite one at the grain boundaries. In the investigated temperature range up to $400{ }^{\circ} \mathrm{C}$, the Young's modulus remains almost constant.
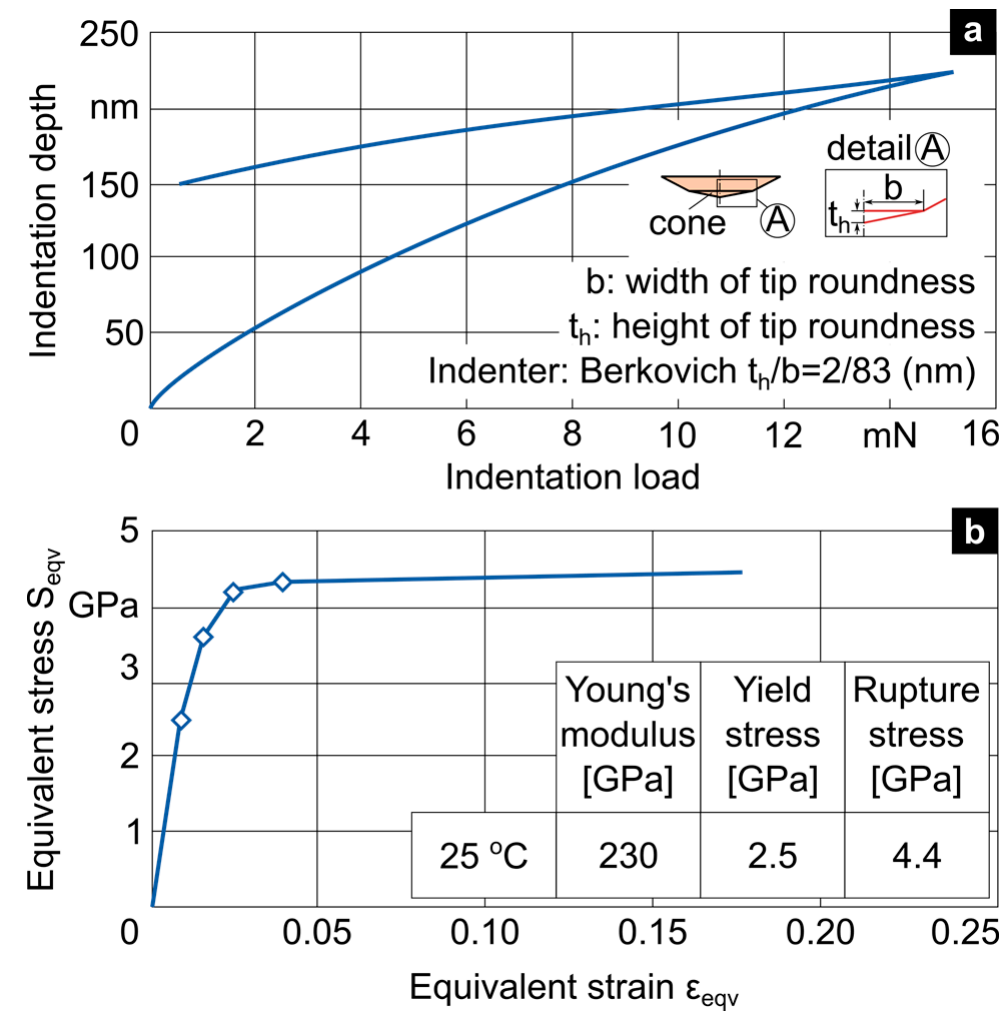

Figure 3. (a) Nanoindentation results on high-speed steel (HSS) at ambient temperature; (b) stress-strain curve of the HSS, attained via a finite element method (FEM)-supported evaluation of the nanoindentation results.

The deterioration of the mechanical properties of the high-speed steel substrate when the temperature grows, can be corroborated when observing the developed imprints after the exercise of the same impact load at ambient and elevated temperatures, as for instance at 25,150 and $250{ }^{\circ} \mathrm{C}$ (see Figure 5). The developed imprints after 1000 impacts, due to the occurring material plastic deformation, were recorded via confocal microscopy. The progressive augmentation of the remaining imprint depth (RID) along with the increase of the temperature is visible.

The latter RID augmentation continues up to about $350{ }^{\circ} \mathrm{C}$. Furthermore, in the investigated temperature range, RID diminishes over $350^{\circ} \mathrm{C}$ up to $400^{\circ} \mathrm{C}$, as demonstrated in Figure 6 . The illustrated course of the RID over the temperature in the range from 25 up to $400{ }^{\circ} \mathrm{C}$ converges sufficiently with the corresponding course of the high-speed steel mechanical properties change versus the temperature, as presented in Figure $4 \mathrm{~b}$. In this way, in the case of coated high-speed specimens, loaded at a constant impact force, the coating deformation, and thus, the developed stresses and a potential coating failure depends, among others, on the test temperature. This will be further elucidated in the next sections. 

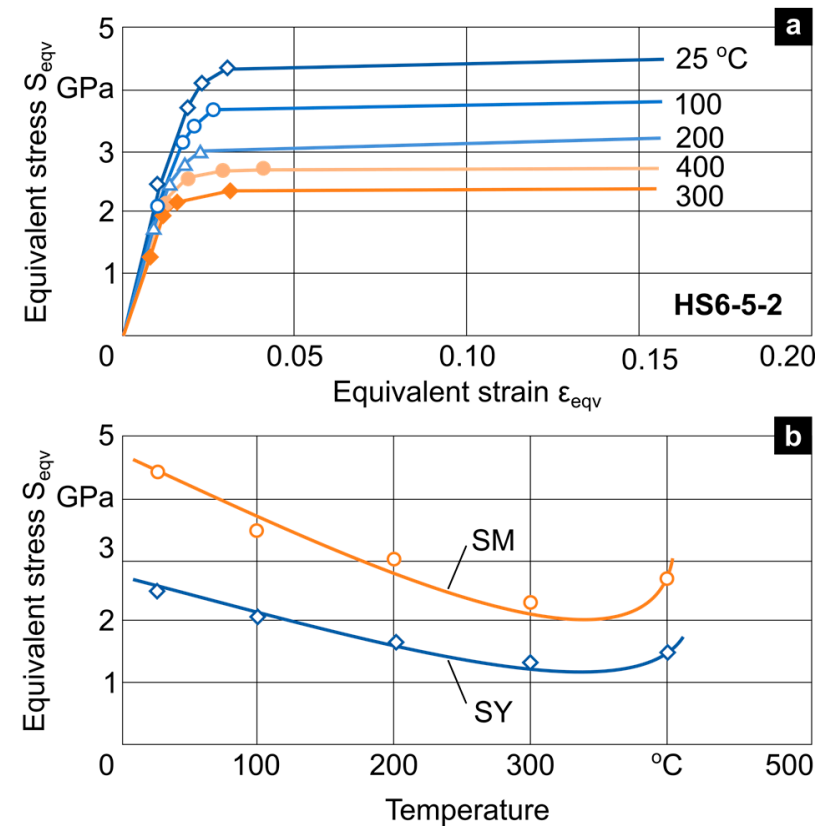

Figure 4. (a) Stress-strain curve of the applied HSS, attained via an FEM supported evaluation of nanoindentation results at elevated temperatures; (b) course of the yield (SY) and rupture stress (SM) of the HSS versus the temperature.
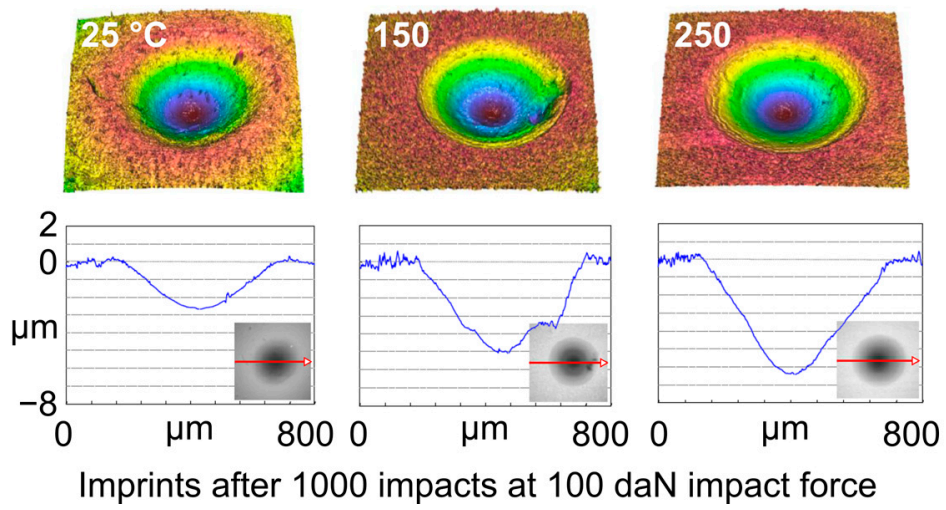

Figure 5. Developed craters on the high-speed steel surfaces after 1000 impacts at constant load and various temperatures.

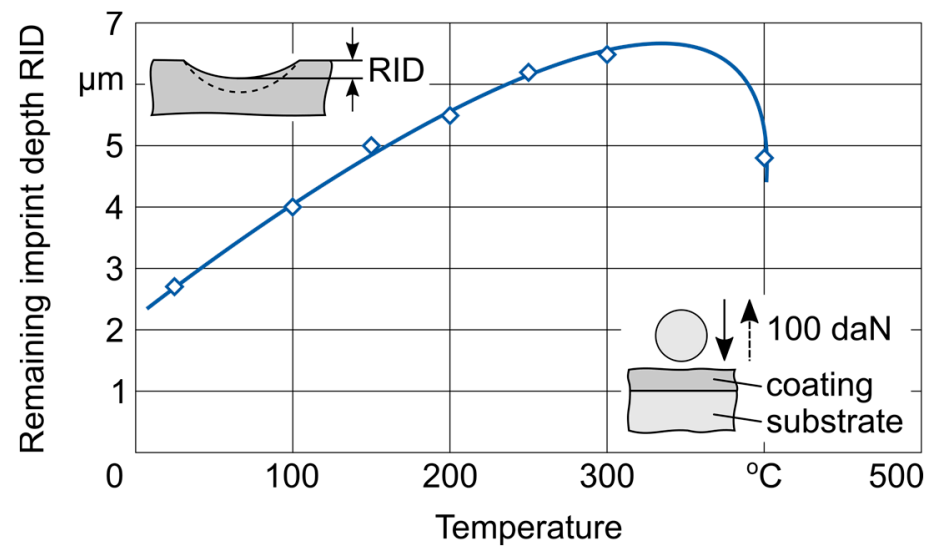

Figure 6. Remaining imprint depth (RID) after 1000 impacts at constant impact force versus the temperature. 


\subsection{Characterization of the Applied DLC Coating's Mechanical Properties}

Implementing the same methodologies for determining the stress-strain data of the applied DLC coating, nanoindentations were carried out, as described in the previous section. The related results at ambient temperature are presented in Figure 7a. Via the evaluation of these results, the stress-strain curve of the DLC coating demonstrated in Figure $7 \mathrm{~b}$ was defined. For minimizing potential inaccuracies, originating from the FEM supported determination of the temperature-dependent substrate yield and rupture strength, in contrast with its modulus of elasticity which remains practically constant in the temperature range between 25 and $400{ }^{\circ} \mathrm{C}$ (see Figure 4), the maximum indentation load was held at the low level of $15 \mathrm{mN}$. In this way, the substrate is only elastically deformed, as the FEM supported calculated stress field in the coating and its substrate exhibited in Figure 8 shows. Thus, when determining the coating mechanical properties at various temperatures, only the constant substrate modulus of elasticity is involved.
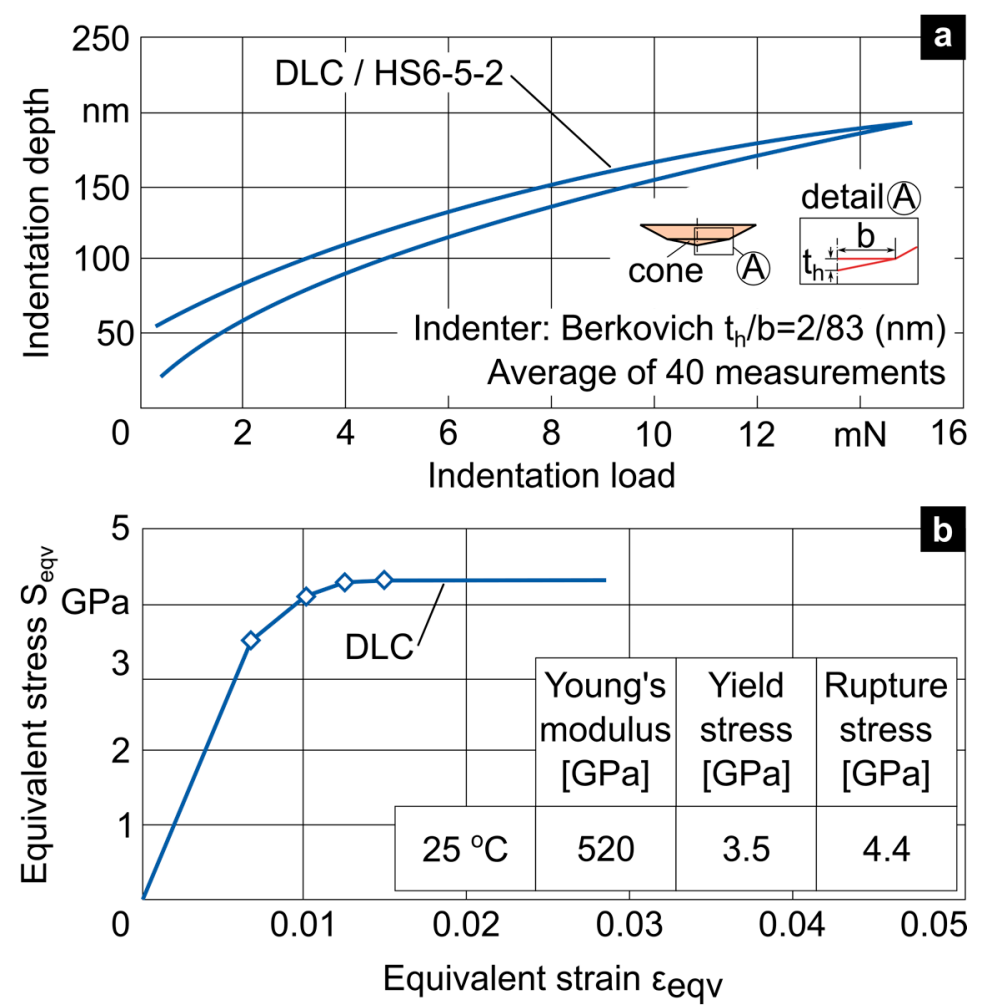

Figure 7. (a) Nanoindentation results on the applied diamond-like carbon (DLC) coating at ambient temperature; (b) stress-strain curve of the DLC coating, attained via an FEM supported evaluation of the nanoindentation results.

The nanoindentation results on the DLC-coated specimens at various temperatures are illustrated in Figure 9a. The obtained maximum indentation depth (ID) and remaining indentation depth (RID) during these measurements are shown in Figure 9b. According to these results and to the corresponding ones at ambient temperature, presented in Figure 7, the coating hardness, and thus deformation, is not affected by the temperature increase up to around $300^{\circ} \mathrm{C}$. Consequently, the coating strength data remain stable up to this temperature. Over $300{ }^{\circ} \mathrm{C}$, the maximum indentation depth starts increasing, a fact indicating the deterioration of the coating's mechanical properties. These results are also corroborated in various publications, as for example in the references [6-8]. The attained data for the coating and its substrate are used to define the developed stress fields in the coating during the impact test at various impact loads and temperatures. 


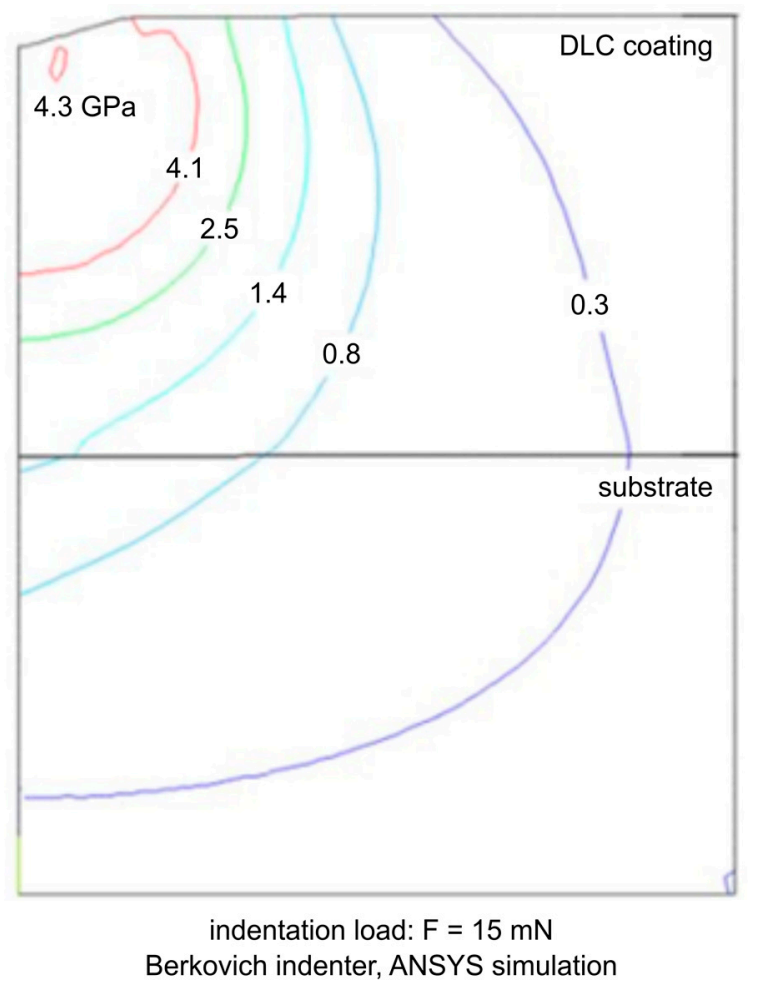

Figure 8. Developed stress fields in the DLC coating and its HSS substrate.
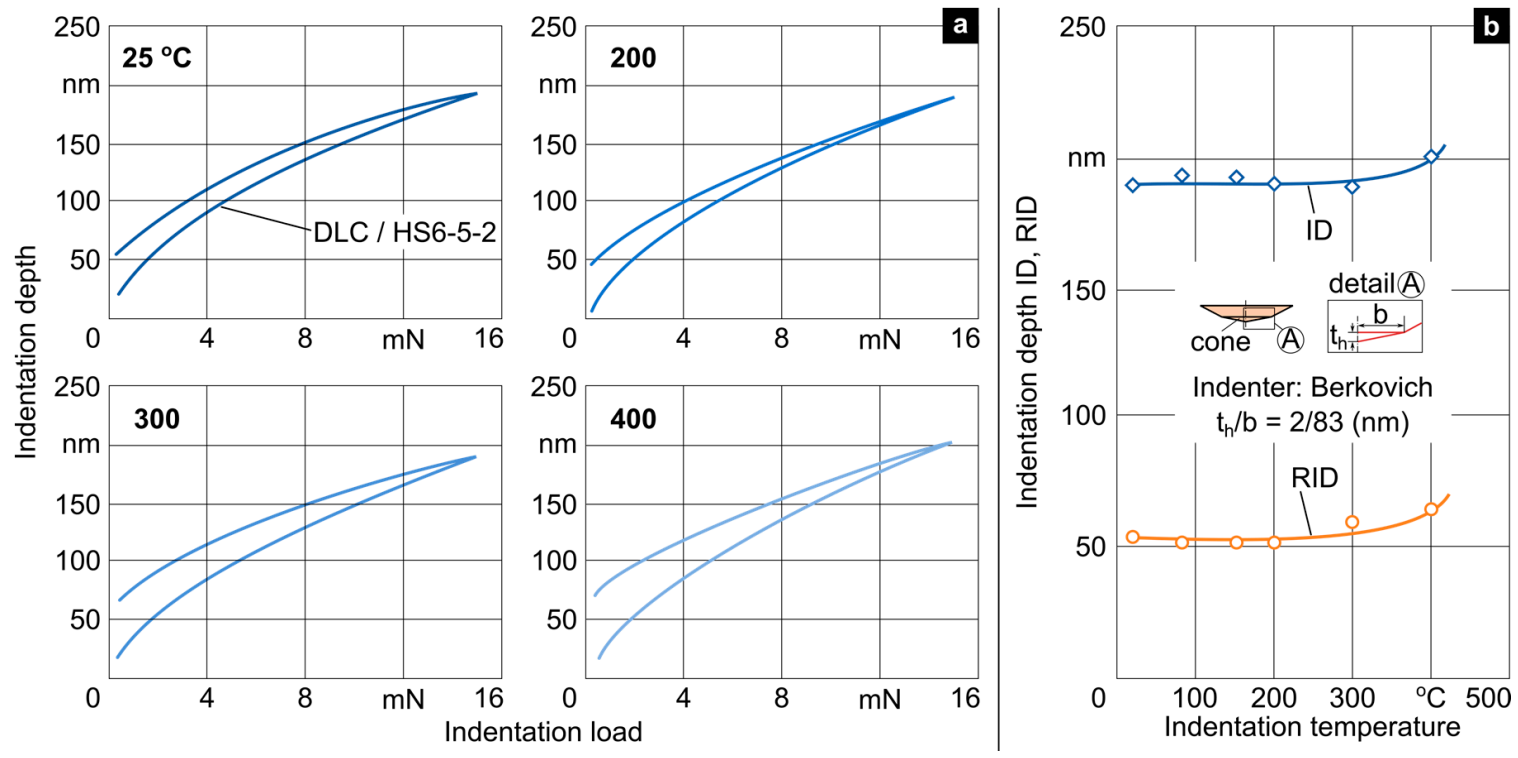

Figure 9. (a) Nanoindentation results on the applied DLC coating at various temperatures; (b) obtained maximum depths (IDs) and RIDs of the DLC coating versus the temperature.

Raman spectroscopy was conducted on the as-deposited and the annealed at $300{ }^{\circ} \mathrm{C}$ DLC coatings to evaluate the nature of their carbon bonding structure (see Figure 10). Hereupon, an argon ion laser with a line of $532 \mathrm{~nm}$ was focused on the surface of the coatings. The measurements were repeated a few times for decreasing the noise level. The obtained Raman spectrum was curve-fitted using two Gaussian functions, peaking at disordered (D-band) and graphite (G-band) modes. The Raman spectra illustrated in Figure 10 are similar in both temperature cases. They revealed an asymmetric $\mathrm{G}$ band centered at approx. $1560 \mathrm{~cm}^{-1}$ and an overlapping broader D band centered at approx. $1360 \mathrm{~cm}^{-1}$. These two characteristic Raman active bands are usually observed in amorphous carbon films due to 
the $s p^{2}$ sites, since its Raman scattering cross section is 50 times larger than that of the $s p^{3}$ ones [22]. The $\mathrm{G}$ band would correspond to the symmetric E2g C-C stretching mode in all $s p^{2}$ sites (both chains and rings), while the D band would be a breathing mode of A1g symmetry involving only those $s p^{2}$ sites in rings [23]. These results show that the carbon bonding structure of the applied DLC coating remains stable in case of annealing up to $300^{\circ} \mathrm{C}$. This fact is in accordance with the unaffected coating hardness up to this temperature as described in Figure 7.

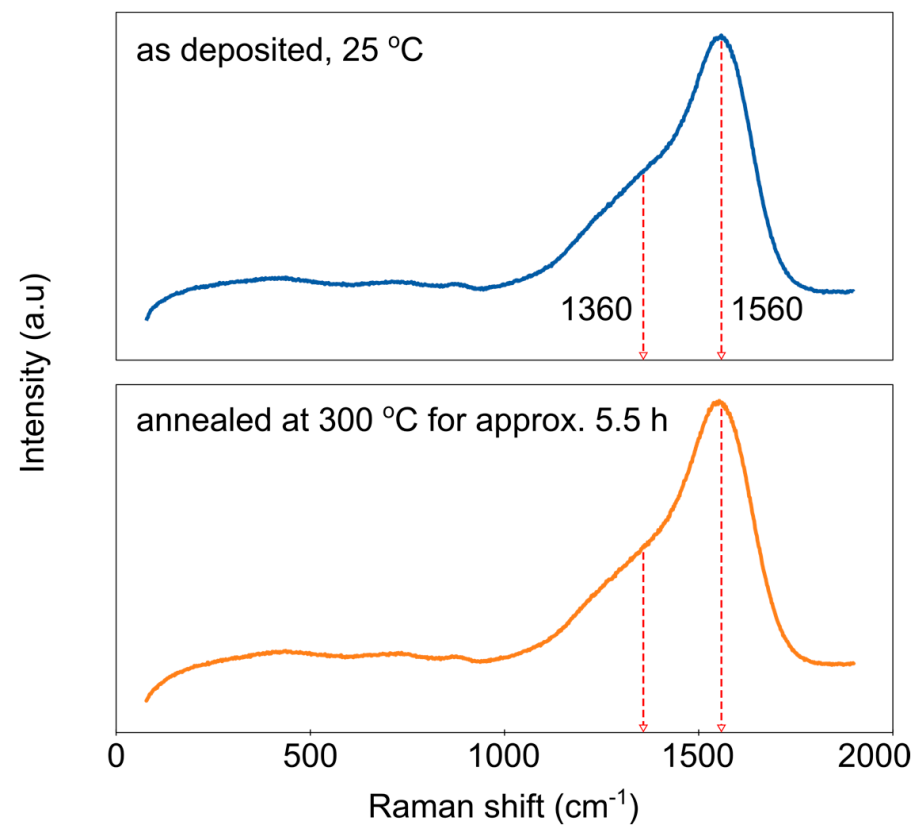

Figure 10. Raman spectra of the applied DLC coating, as-deposited and annealed at $300^{\circ} \mathrm{C}$.

\subsection{DLC Coatings' Fatigue Endurance after $10^{6}$ Impacts at Various Temperatures}

In the performed impact tests, the coating failure evolution was recorded with the aid of the failed area ratio (FR). This magnitude is defined as the ratio of the coating failed area (FA) to the contact area (CA) (crater area) between the ball indenter and the coated specimen's surface. The coatings' failed area (FA) within the crater area is calculated via image processing of backscattered electron analysis results, as explained in Figure 11.

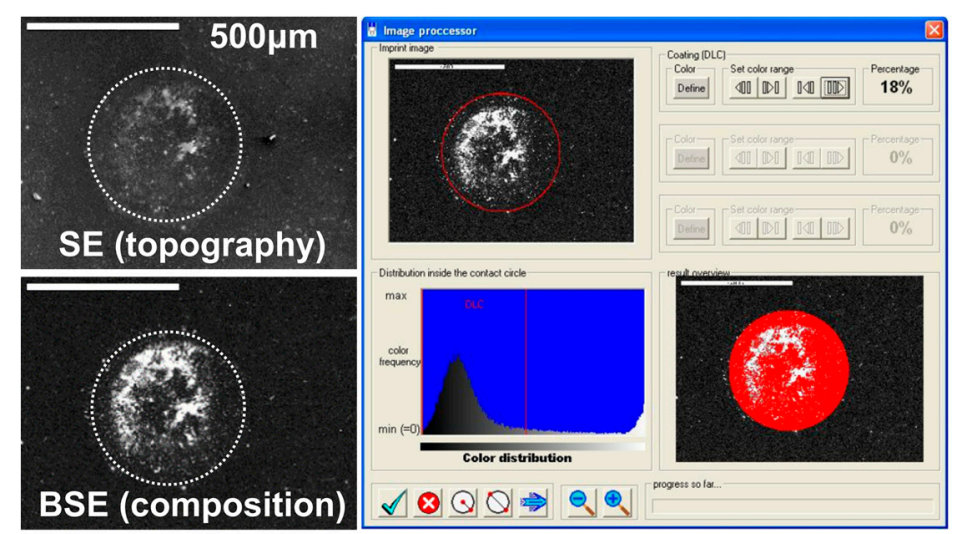

Imprint after $10^{6}$ impacts at 120 daN impact force $(F R=0.18)$

SE: secondary electrons, BSE: backscattered electrons

Figure 11. Evaluation of SEM backscattered electron analysis photos via image processing to determine failed area ratio (FR). 
By means of the parameter FR, the coating wear status in the contact area between the high-speed steel substrate and the ball indenter is captured in Figure 12, after $10^{6}$ impacts at ambient temperature and various forces. The coating possesses fatigue endurance for repetitive impacts up to a critical force of approximately $180 \mathrm{daN}$. At this load, the DLC coating fails after $10^{6}$ impacts. The developed coating failed area appears in the vicinity of the imprint's perimeter, as it can be observed in the corresponding SEM photo in the upper part of Figure 13. In this imprint region, the occurring stress exceeds the coating fatigue endurance stress, thus leading to the coating damage.

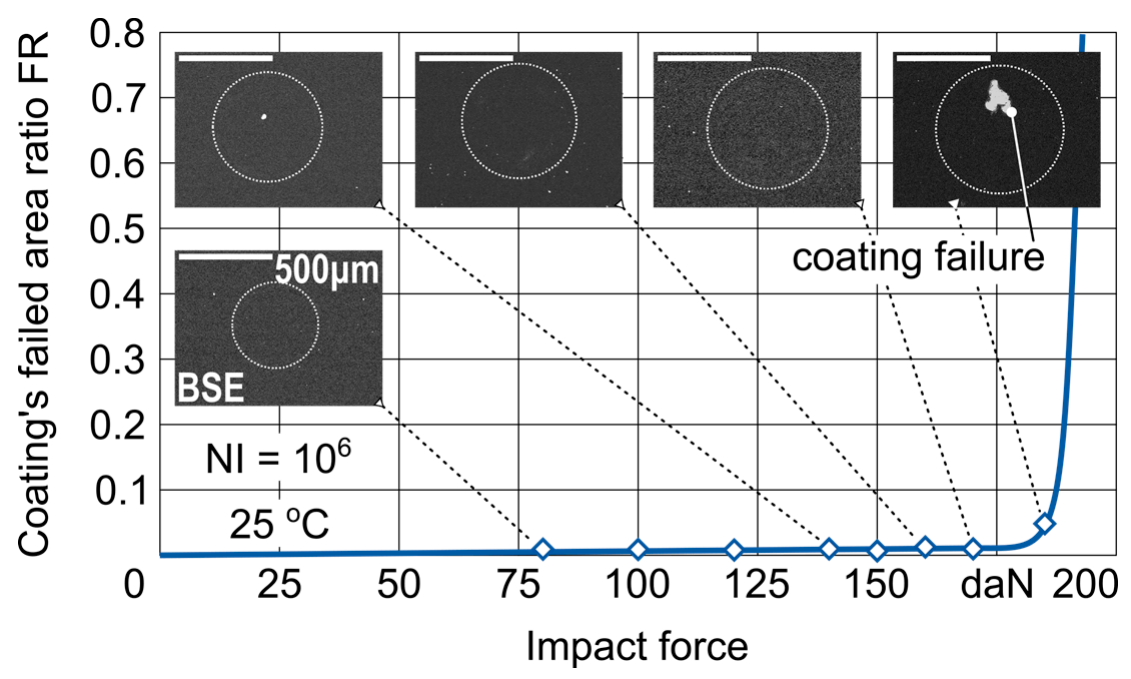

Figure 12. Impact test imprints on the DLC-coated HSS specimens and corresponding FRs at various impact forces after $10^{6}$ impacts.

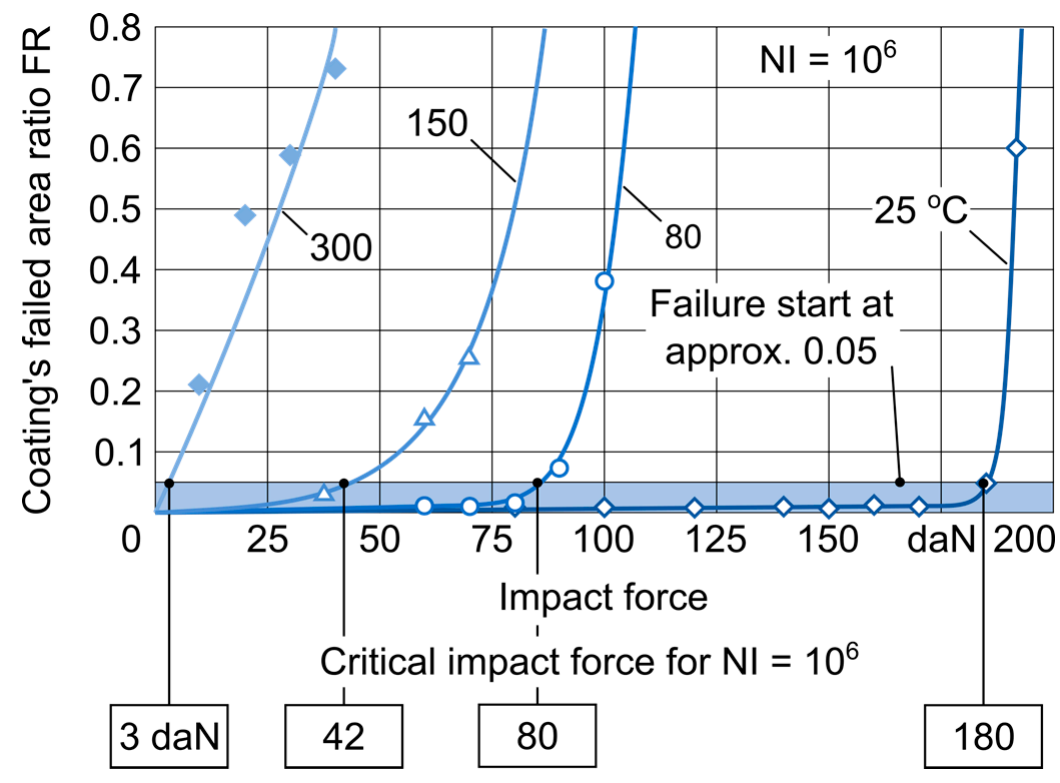

Figure 13. FR of the DLC coating after $10^{6}$ impacts at various temperatures and impact forces.

A significant reduction of the critical impact force develops, when the test temperature increases stepwise from 25 up to $300{ }^{\circ} \mathrm{C}$, as shown in Figure 14 . At the temperature of $300{ }^{\circ} \mathrm{C}$, the DLC coating fails after $10^{6}$ impacts, at impact forces of only 3 daN. After the coating failure initiation, the coating removal rate from the substrate surface is almost equally intensive in all tested temperature cases, as the curves of Figure 13 indicate. 


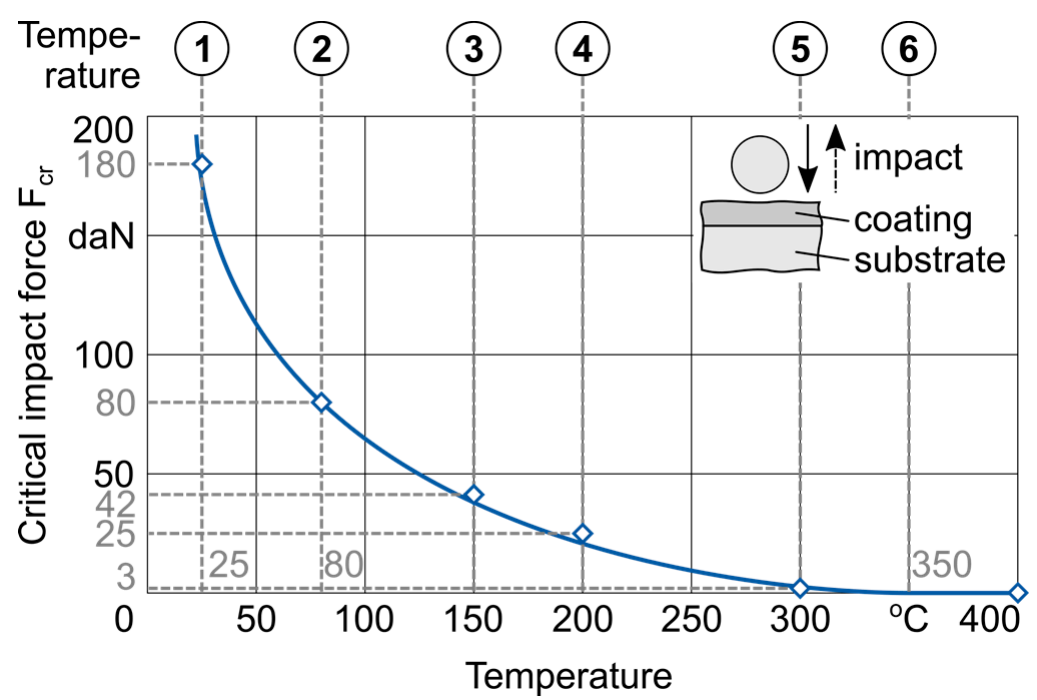

Figure 14. Critical impact force associated with coating fatigue endurance at $10^{6}$ impacts versus temperature.

The exponential diminishing of the critical impact force versus the temperature is illustrated in Figure 14. The impact force, and thus the coating fatigue endurance at $10^{6}$ impacts is practically nullified at temperatures larger than $300^{\circ} \mathrm{C}$. Using this diagram, the critical impact forces associated with the temperatures 1 to 6, as shown in Figure 14, can be determined. Hereupon, if the impact force remains constant, due to the more intensive substrate deformation when the temperature increases over the ambient one, the developed coating stresses grow too. Thus, although the coating retains its strength properties when the temperature increases up to approximately $300^{\circ} \mathrm{C}$, it might fail at a lower load, due to the substrate mechanical data deterioration and consequently larger deformation.

For the presented temperature-dependent critical forces and considering the mechanical properties of the DLC coating and its substrate introduced in the previous sections, the corresponding stress fields were calculated by means of the described impact test FEM simulation. In this way, it was possible to explain theoretically the experimental results.

\subsection{Theoretical Explanation of the Attained Experimental Results via FEM Supported Calculations}

Characteristic results obtained via the FEM supported simulation of the impact test are demonstrated in Figure 15. The illustrated stress fields developed in the coating and its substrate during the loading and relaxation phases of the impact test refer to an impact load and temperature of $100 \mathrm{daN}$ and $25^{\circ} \mathrm{C}$, respectively. The mechanical properties of the coating and substrate correspond to the presented ones in Figures 3 and 4. The coating follows the substrate deformation resembling a spherical surface. As explained below, the maximum stresses in the coating structure appear in the vicinity of the crater due to bending, where the coating failure starts, if the range between the developed maximum stresses during loading and relaxation exceeds the corresponding fatigue endurance safe stress range. An example of such a coating failure initiation in the vicinity of the crater was displayed in Figure 12.

Using the previous FEM supported simulation of the impact test, the stress fields developed in the coating during the impact test loading and relaxation phases were calculated at the experimentally determined critical forces and corresponding temperatures presented in Figure 14. Related results are depicted in Figure 16. The equivalent stress fields developed in the coating during loading and relaxation at the critical impact force of $180 \mathrm{daN}$ corresponding to ambient temperature of $25^{\circ} \mathrm{C}$ are captured in the figure. According to these stress fields, the maximum equivalent stresses amount to $4.28 \mathrm{GPa}$ and $1.68 \mathrm{GPa}$ for loading and relaxation, respectively. These data and the coating mechanical properties are required for the establishment of the DLC coating Smith-like diagram, as described in the following. By conducting further similar FEM calculations, the maximum equivalent stresses during 
the loading and relaxation impact test phases at the critical fatigue endurance forces, associated with elevated temperatures were defined. These are listed in Table 1. In case 5, due to the low critical impact force, the substrate behaves elastically at this load, i.e., no remaining stresses occur in the coating during the relaxation. Moreover, in the case where the impact force remains constant, due to the more intensive substrate deformation when the temperature increases, the developed coating stresses grow as well. Thus, although the coating retains its strength properties when the temperature increases at least up to $150^{\circ} \mathrm{C}$, as will be further explained, the coating may fail at a lower load compared to ambient one, due to the substrate's mechanical data deterioration and consequently the coating's larger deformation.
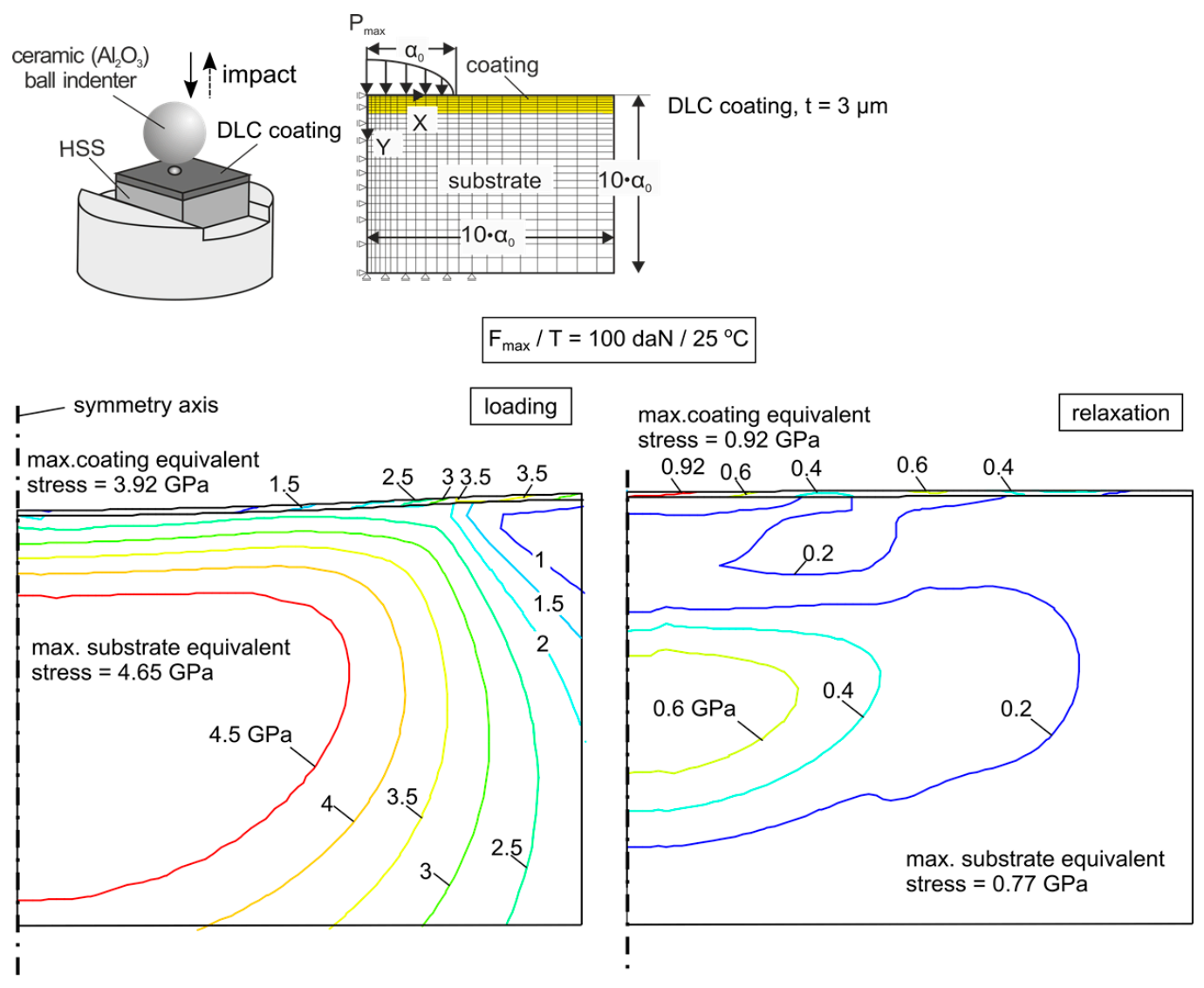

Figure 15. FEM supported calculation of the developed maximum and remaining stress fields in the coating and its substrate during the impact test loading and relaxation phases.

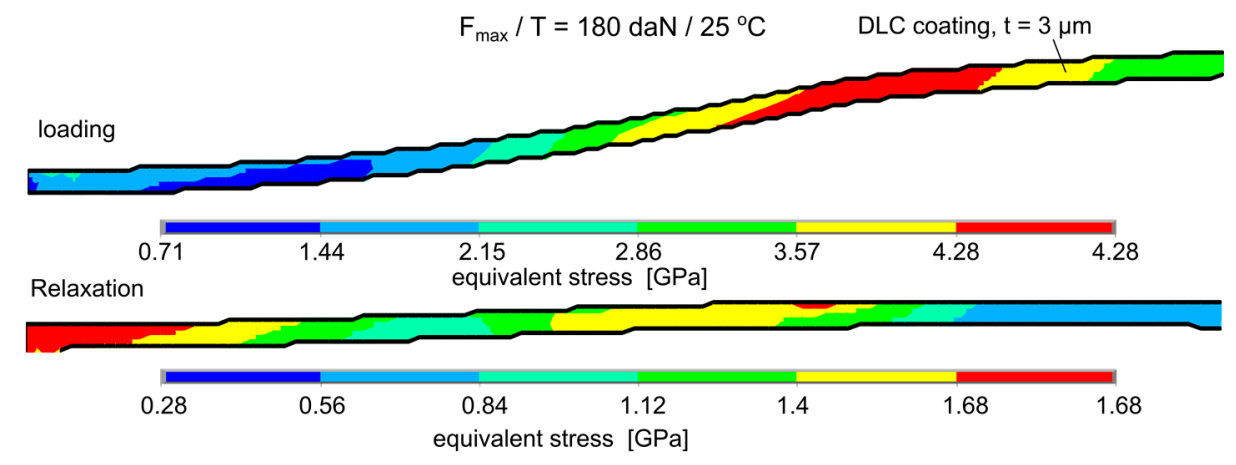

Figure 16. Developed maximum and remaining stress fields in the DLC coating at the fatigue endurance critical force and ambient temperature. 
Table 1. Maximum equivalent stresses during loading and relaxation at the fatigue endurance critical forces at various temperatures.

\begin{tabular}{ccccc}
\hline Case Nr. & Temperature $\left[{ }^{\circ} \mathbf{C}\right.$ ] & $\begin{array}{c}\text { Critical Impact } \\
\text { Force F }[\text { daN] }\end{array}$ & $\begin{array}{c}\text { Maximum Equivalent Stress [GPa] } \\
\text { Loading }\end{array}$ & Relaxation \\
\hline 1 & 25 & 180 & 4.28 & 1.68 \\
2 & 80 & 80 & 3.84 & 1.02 \\
3 & 150 & 42 & 3.48 & 0.66 \\
4 & 200 & 25 & 2.88 & 0.48 \\
5 & 300 & 3 & 0.88 & 0 \\
6 & 350 & 0 & 0 & 0 \\
\hline
\end{tabular}

The experimentally attained results concerning the temperature-dependent fatigue endurance critical forces, can be explained with the aid of the applied DLC coating Smith-like diagram demonstrated in Figure 17. This diagram was created implementing the methodologies described in references [6,7], using experimental results of dynamic repetitive impact tests and substrate as well as coating mechanical properties achieved by quasi-static tests. More specifically, the required data to establish this diagram are the critical impact force experimentally determined at ambient temperature, the corresponding fatigue endurance stress range, calculated as previously described, as well as the coating's mechanical properties. The reduction of the critical impact force up to the temperature of approximately $150^{\circ} \mathrm{C}$, is in accordance with the DLC coating's Smith-like diagram (see Figure 17). This can be explained, considering that the coating properties remain practically invariant up to the temperature of $150{ }^{\circ} \mathrm{C}$ and the developed stresses increase, induced by the substrate's larger deformation due to the deterioration of its mechanical properties. In this way, the presented Smith-like diagram monitors the fatigue safe stress ranges corresponding to certain critical impact forces when the temperature increases. In contrast to cases 1 to 3 , the calculated safe stress range associated with a critical impact force of about $25 \mathrm{daN}$ and temperature of $20{ }^{\circ} \mathrm{C}$ (case 4 ) does not converge with that one occurring from the Smith-like diagram. At this impact force and temperature, the experimentally-analytically determined safe stress range is between 2.88 and $0.48 \mathrm{GPa}$ (see Table 1), whereas the corresponding range according to the Smith-like diagram is between 2.9 and $0.3 \mathrm{GPa}$ approximately. At a further increase of the temperature up to $300{ }^{\circ} \mathrm{C}$, the impact force and the fatigue safe endurance range are drastically reduced (case 5), whereas at $350{ }^{\circ} \mathrm{C}$, these parameters are nullified. On the other hand, the coating's fatigue safe area deviates significantly from the Smith-like diagram elaborated assuming constant mechanical properties of DLC coatings. This result can be explained with the aid of the displacement of non-bonded hydrogens facilitated when the temperature increases over $150{ }^{\circ} \mathrm{C}$, and thus, creating a coating brittleness without affecting practically the coating hardness. Over approximately $300^{\circ} \mathrm{C}$, mechanisms like the desorption of hydrogen and hydrocarbon fragments [15] as well as crystalline structure conversions from $s p^{3}$ to $s p^{2}[16,17,24]$ are activated, restricting the coating load capacity, and thus its fatigue endurance.

It is worth mentioning that the abovementioned mechanisms in the temperature range between 150 and $300{ }^{\circ} \mathrm{C}$ are triggered by the energy which is introduced into the coating structure during its repetitive intensive deformation imposed by the rebound impacts. The thermal energy alone for heating up the coating and its substrate up to $300^{\circ} \mathrm{C}$ is not sufficient to impose structural and mechanical properties changes, as the related Raman spectroscopy and nanoindentations results demonstrated. That means, the DLC coating mechanical properties change over $150^{\circ} \mathrm{C}$ is an interaction of thermal and mechanical loads simultaneously, accelerating the coating failure. The strain rate associated with the time course of the applied mechanical loads is a significant factor affecting the coating fatigue endurance $[25,26]$. Therefore, the impact time of the applied forces in the conducted impact tests of approximately $0.45 \mathrm{~ms}$ (see Figure 1c), was adjusted to be practically equal to the corresponding time exercised on the considered machine elements during their operation. 


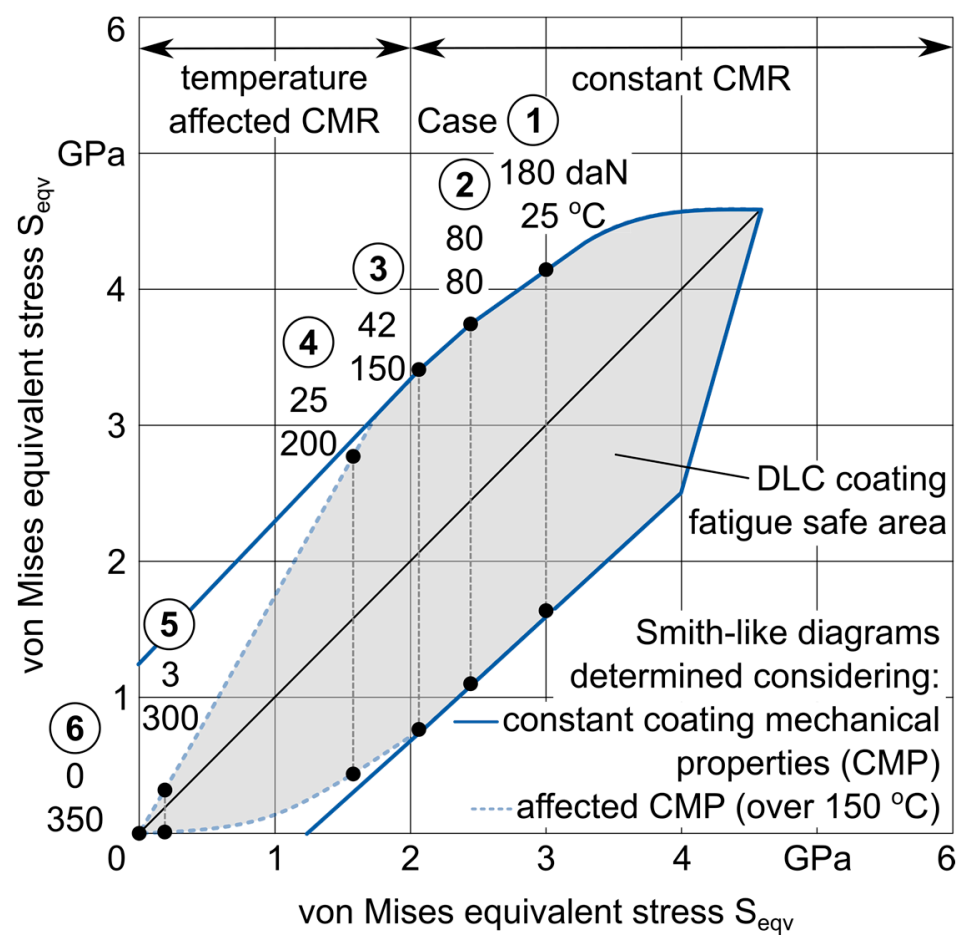

Figure 17. DLC coating Smith-like diagrams determined considering constant mechanical properties as well as temperature affected ones.

\section{Conclusions}

DLC coatings retain their mechanical properties up to approximately $300^{\circ} \mathrm{C}$. However, when the temperature increases over the ambient one, their fatigue endurance critical force is significantly reduced due to the high-speed steel substrate strength deterioration, and thus more intensive coating deformation. Moreover, the coating load capacity is further restricted over $150{ }^{\circ} \mathrm{C}$, due to the coating brittleness induced by non-bonded hydrogen displacements, and over $300{ }^{\circ} \mathrm{C}$, due to desorption of hydrogen and hydrocarbon fragments. Considering the coating Smith-like diagram established via an FEM supported evaluation of experimental results at ambient temperature, the fatigue endurance safe stress ranges up to $150{ }^{\circ} \mathrm{C}$ can be analytically determined. These contribute to the prediction of temperature-dependent permitted loads for a fatigue safe operation of DLC coatings on machine elements' surfaces.

Funding: This research received no external funding.

Acknowledgments: The support of the Laboratory for Machine Tools and Manufacturing Engineering EEDM of the School of Mechanical Engineering, of the Aristotle University Thessaloniki in Greece is gratefully acknowledged.

Conflicts of Interest: The author declares no conflict of interest.

\section{References}

1. Al Mahmud, K.A.H.; Kalam, M.A.; Masjuki, H.H.; Mobarak, H.M.; Zulkifli, N.W.M. An updated overview of diamond-like carbon coating in tribology. Crit. Rev. Solid State Mater. Sci. 2015, 40, 90-118. [CrossRef]

2. Liu, Y.; Erdemir, A.; Meletis, E.I. An investigation of the relationship between graphitization and frictional behavior of DLC coatings. Surf. Coat. Technol. 1996, 86-87, 564-568. [CrossRef]

3. Ma, T.-B.; Hu, Y.-Z.; Wang, H. Molecular dynamics simulation of shear-induced graphitization of amorphous carbon films. Carbon 2009, 47, 1953-1957. [CrossRef]

4. Santiago, J.A.; Fernández-Martínez, I.; Sánchez-López, J.C.; Rojas, T.C.; Wennberg, A.; Bellido-González, V.; Molina-Aldareguia, J.M.; Monclús, M.A.; González-Arrabal, R. Tribomechanical properties of hard Cr-doped DLC coatings deposited by low-frequency HiPIMS. Surf. Coat. Technol. 2020, 382, 124899. [CrossRef] 
5. Johnston, S.V.; Hainsworth, S.V. Effect of DLC coatings on wear in automotive applications. Surf. Eng. 2005, 2, 67-71. [CrossRef]

6. Bouzakis, K.-D.; Skordaris, G.; Bouzakis, A. Impact test applications in surface engineering for coatings characterization. In Proceedings of the 10th International Congress on Machining, Antalya, Turkey, 7-9 November 2019; pp. 201-207.

7. Bouzakis, K.-D.; Vidakis, N.; David, K. The concept of an advanced impact tester supported by evaluation software for the fatigue strength characterization of hard layered media. Thin Solid Films 1999, 355-356, 322-329. [CrossRef]

8. Bouzakis, K.-D.; Michailidis, N.; Skordaris, G.; Bouzakis, E.; Biermann, D.; M'Saoubi, R. Cutting with coated tools: Coating technologies, characterization methods and performance optimization. CIRP Ann. Manuf. Technol. 2012, 61, 703-723. [CrossRef]

9. Bouzakis, K.-D.; Mirisidis, I.; Michailidis, N.; Lili, E.; Sampris, A.; Erkens, G.; Cremer, R. Wear of Tools Coated with Various PVD Films: Correlation with Impact Test Results by Means of FEM Simulations. Plasma Process. Polym. 2007, 4, 301-310. [CrossRef]

10. Bouzakis, K.-D.; Batsiolas, M.; Maliaris, G.; Pappa, M.; Bouzakis, E.; Skordaris, G. New methods for characterizing coating properties at ambient and elevated temperatures. Key Eng. Mater. 2010, 438, 107-114. [CrossRef]

11. Bouzakis, K.-D.; Michailidis, N.; Hadjiyiannis, S.; Skordaris, G.; Erkens, G. Continuous FEM simulation of the nanoindentation: Actual indenter tip geometries, material elastoplastic deformation laws and universal hardness. Z. Metallkd. 2002, 93, 862-869. [CrossRef]

12. Bouzakis, K.-D.; Michailidis, N.; Hadjiyiannis, S.; Skordaris, G.; Erkens, G. The effect of specimen roughness and indenter tip geometry on the determination accuracy of thin hard coatings stress-strain laws by nanoindentation. Mater. Charact. 2002, 49, 149-156. [CrossRef]

13. Bouzakis, K.-D.; Michailidis, N. Deviations in determining coatings' and other materials' mechanical properties, when considering different indenter tip geometries and calibration procedures. Surf. Coat. Technol. 2007, 202, 1108-1112. [CrossRef]

14. Bouzakis, K.-D.; Pappa, M.; Maliaris, G.; Michailidis, N. Fast determination of parameters describing manufacturing imperfections and operation wear of nanoindenter tips. Surf. Coat. Technol. 2013, 215, 218-223. [CrossRef]

15. Zůda, J.; Buršíková, V.; Čech, J.; St'ahel, P. Thermal Stability of Diamond Like Carbon Thin Films Prepared Using Plasma Enhanced Chemical Vapor Deposition. In Proceedings of the 5th International Conference Juniormat '05, Brno, Czech Republic, 20-21 September 2005; pp. 47-50.

16. Tallant, D.R.; Parmeter, J.E.; Siegal, M.P.; Simpson, R.L. The thermal stability of diamond-like carbon. Diam. Relat. Mater. 1995, 4, 191-199. [CrossRef]

17. Buršíková, V.; Navrátil, V.; Zajíčková, L.; Janča, J. Temperature dependence of mechanical properties of DLC/Si protective coatings prepared by PECVD. Mater. Sci. Eng. A 2002, 324, 251-254. [CrossRef]

18. Bouzakis, K.-D.; Asimakopoulos, A.; Skordaris, G.; Pavlidou, E.; Erkens, G. The inclined impact test: A novel method for the quantification of the adhesion properties of PVD films. Wear 2007, 262, 1471-1478. [CrossRef]

19. Bouzakis, K.-D.; Charalampous, P.; Skordaris, G.; Dimofte, F.; Ene, N.M.; Ehinger, R.; Gardner, S.; Modrzejewski, B.S.; Fetty, J.R. Fatigue and adhesion characterization of DLC coatings on steel substrates by perpendicular and inclined impact tests. Surf. Coat. Technol. 2015, 275, 207-213. [CrossRef]

20. Skordaris, G.; Bouzakis, K.-D.; Charalampous, P.; Kotsanis, T.; Bouzakis, E.; Bejjani, R. Bias voltage effect on the mechanical properties, adhesion and milling performance of PVD films on cemented carbide inserts. Wear 2018, 404-405, 50-61. [CrossRef]

21. Klocke, F. Manufacturing Processes 1; RWTH, Ed.; Springer: Berlin/Heidelberg, Germany, 2011; pp. $107-109$. [CrossRef]

22. Schwan, J.; Ulrich, S.; Roth, H.; Ehrhardt, H.; Silva, S.R.P.; Robertson, J.; Samlenski, R.; Brenn, R. Tetrahedral amorphous carbon films prepared by magnetron sputtering and dc ion plating. J. Appl. Phys. 1996, 79, 1416-1422. [CrossRef]

23. Schwan, J.; Ulrich, S.; Batori, V.; Ehrhardt, H.; Silva, S.R.P. Raman spectroscopy on amorphous carbon films. J. Appl. Phys. 1996, 80, 440-447. [CrossRef]

24. Erdemir, A. The role of hydrogen in tribological properties of diamond-like carbon films. Surf. Coat. Technol. 2001, 146-147, 292-297. [CrossRef] 
25. Bouzakis, K.-D.; Maliaris, G.; Makrimallakis, S. Strain rate effect on the fatigue failure of thin PVD coatings: An investigation by a novel impact tester with adjustable repetitive force. Int. J. Fatigue 2012, 44, 89-97. [CrossRef]

26. Wheeler, J.M.; Gunner, A.G. Analysis of failure modes under nano-impact fatigue of coatings via high-speed sampling. Surf. Coat. Technol. 2013, 232, 264-268. [CrossRef]

(C) 2020 by the author. Licensee MDPI, Basel, Switzerland. This article is an open access article distributed under the terms and conditions of the Creative Commons Attribution (CC BY) license (http://creativecommons.org/licenses/by/4.0/). 